\title{
Relationship between Physicians' Moral Sensitivity and Patients' Satisfaction: A Survey in Educational Hospitals in Tehran, Iran
}

\author{
Majid Taheri ${ }^{1}$, Mohammad Tavakol ${ }^{2}$, Amir Almasi-Hashiani ${ }^{3}$, Seidamir Pasha Tabaeian ${ }^{4}$, \\ Mehri Mohammadi ${ }^{4}$, Morteza Ghasemi $^{5}$, and Mahmoud Abbasi ${ }^{6}$ \\ ${ }^{1}$ Affiliation not available \\ ${ }^{2}$ University of Tehran \\ ${ }^{3}$ Arak University of Medical Sciences \\ ${ }^{4}$ Iran University of Medical Sciences \\ ${ }^{5}$ Islamic Azad University of Arak, Arak-Iran \\ ${ }^{6}$ Shahid Beheshti University of Medical Sciences
}

July 23, 2020

\begin{abstract}
Objective: The aim of the present study is to assess interactions between the moral sensitivity of physicians and satisfaction of patients. Materials and Methods: The present study is a cross-sectional research performed on physicians and patients in Tehran, Iran. The physicians were selected through census method, and patients were selected using quota sampling for equally selecting each physician from each work shift. Data were collected through a standard questionnaire of the physicians' moral sensitivity for decision-making and a researcher-made patient satisfaction questionnaire. Data were analyzed by the SPSS software version 23. Ethical Considerations: The study received ethical approval by Ethics Committee of Shahid Beheshti University of Medical Sciences. After explaining the objectives of the study, all participants completed and signed the written consent form. Results: The mean score for physicians' moral sensitivity was $91.6 \pm 0.63$ (out of 100) which shows a high level of moral sensitivity. The highest scores were related to the domain of "honesty and benevolence" and the lowest score was related to the domain of "The level of career knowledge". The average patient satisfaction was $61.97 \pm 3.55$ out of the total score (23-115) which shows a moderate level of satisfaction with the highest scores in the domain of "professionalism" and the lowest scores were related to the domain of "Technical Quality of Care". According to the results, physician moral sensitivity and patient satisfaction are correlated $(\mathrm{r}=0.611)$. Conclusion: Regarding the observed relationship between physicians' moral sensitivity and patients' satisfaction, it is suggested that improving patient satisfaction, adopting appropriate strategies like performing periodic evaluation of this phenomenon and providing some codified training in this regard are required to increase the level of moral sensitivity of physicians and provide high-quality care
\end{abstract}

\section{Hosted file}

Moral Sensitivity.doc available at https://authorea.com/users/345417/articles/471657relationship-between-physicians-moral-sensitivity-and-patients-satisfaction-a-surveyin-educational-hospitals-in-tehran-iran

\section{Hosted file}

Tables.doc available at https://authorea.com/users/345417/articles/471657-relationshipbetween-physicians-moral-sensitivity-and-patients-satisfaction-a-survey-in-educationalhospitals-in-tehran-iran 